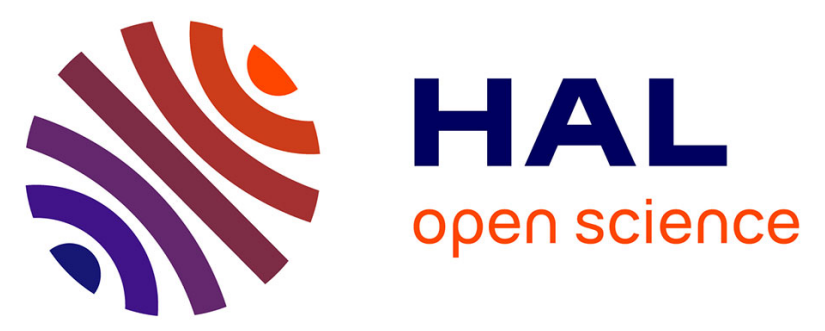

\title{
A multicenter randomized phase II study of sequential epirubicin/cyclophosphamide followed by docetaxel with or without celecoxib or trastuzumab according to HER2 status, as primary chemotherapy for localized invasive breast cancer patients
}

Jean-Yves Pierga, Suzette Delaloge, Marc Espié, Etienne Brain, Brigitte

Sigal-Zafrani, Marie-Christine Mathieu, Philippe Bertheau, Jean Marc

Guinebretière, Marc Spielmann, Alexia Savignoni, et al.

\section{To cite this version:}

Jean-Yves Pierga, Suzette Delaloge, Marc Espié, Etienne Brain, Brigitte Sigal-Zafrani, et al.. A multicenter randomized phase II study of sequential epirubicin/cyclophosphamide followed by docetaxel with or without celecoxib or trastuzumab according to HER2 status, as primary chemotherapy for localized invasive breast cancer patients. Breast Cancer Research and Treatment, 2010, 122 (2), pp.429-437. 10.1007/s10549-010-0939-3 . hal-00537245

\section{HAL Id: hal-00537245 \\ https://hal.science/hal-00537245}

Submitted on 18 Nov 2010

HAL is a multi-disciplinary open access archive for the deposit and dissemination of scientific research documents, whether they are published or not. The documents may come from teaching and research institutions in France or abroad, or from public or private research centers.
L'archive ouverte pluridisciplinaire HAL, est destinée au dépôt et à la diffusion de documents scientifiques de niveau recherche, publiés ou non, émanant des établissements d'enseignement et de recherche français ou étrangers, des laboratoires publics ou privés. 


\title{
A multicenter randomized phase II study of sequential epirubicin/ cyclophosphamide followed by docetaxel with or without celecoxib or trastuzumab according to HER2 status, as primary chemotherapy for localized invasive breast cancer patients
}

\author{
Jean-Yves Pierga $\cdot$ Suzette Delaloge $\cdot$ Marc Espié $\cdot$ Etienne Brain $\cdot$ \\ Brigitte Sigal-Zafrani - Marie-Christine Mathieu • Philippe Bertheau • \\ Jean Marc Guinebretière · Marc Spielmann · Alexia Savignoni • \\ Michel Marty \\ Received: 14 December 2009/Accepted: 6 May 2010/Published online: 18 May 2010 \\ (C) Springer Science+Business Media, LLC. 2010
}

\begin{abstract}
To assess anti-tumor activity of sequential epirubicin/cyclophosphamide followed by docetaxel with the randomized addition of celecoxib in HER2 negative patients or trastuzumab in HER2 positive patients. From May 2004 till October 2007, 340 patients with stage II and III breast adenocarcinoma, ineligible for breast conserving surgery, received eight sequential three weekly cycles of EC-D [epirubicin $\left(75 \mathrm{mg} / \mathrm{m}^{2}\right)$-cyclophosphamide $\left(750 \mathrm{mg} / \mathrm{m}^{2}\right)$ for four cycles followed by docetaxel $\left(100 \mathrm{mg} / \mathrm{m}^{2}\right)$ for four cycles]. HER2-negative patients $(N=220)$ were randomized to receive concomitantly with docetaxel celecoxib $800 \mathrm{mg}$ /day during cycles $5-8$ or no additional treatment, while HER2-positive patients confirmed by FISH $(N=120)$ were randomized to trastuzumab concomitant to docetaxel $(8 \mathrm{mg} / \mathrm{kg}$ then $6 \mathrm{mg} / \mathrm{kg}$ IV every 3 weeks) or no additional preoperative treatment. In the HER2 negative group, pCR (grade 1 and 2 of Chevallier's classification) was observed in 11.5 and $13 \%$ of patients treated without and with neoadjuvant Celecoxib, respectively. In the HER2 positive group, pCR rate reached
\end{abstract}

J.-Y. Pierga ( $₫)$. B. Sigal-Zafrani · A. Savignoni Institut Curie, 26 rue d'Ulm, 75005 Paris, France

e-mail: jean-yves.pierga@curie.net

S. Delaloge · M.-C. Mathieu · M. Spielmann

Institut Gustave Roussy, Villejuif, France

M. Espié · P. Bertheau · M. Marty

Saint Louis University Hospital, Paris, France

E. Brain · J. M. Guinebretière

Centre René Huguenin, Saint Cloud, France

J.-Y. Pierga

Université Paris Descartes, Paris, France
$26 \%$ in those who received neoadjuvant trastuzumab versus $19 \%$ in the others. There was no unexpected toxicity, no cardiac toxicity, and no toxic death. Triple negative breast cancers experience the highest $\mathrm{pCR}$ rate of $30 \%$. Celecoxib is not likely to improve pCR rates in addition to EC-D in patients with HER2-negative tumor. In HER2-positive tumor patients, trastuzumab added to ECD leads to increased $\mathrm{pCR}$ rates. It was the only combination to deserve further study according to the two-stage Fleming's design used in this trial.

Keywords Breast cancer - Neoadjuvant chemotherapy · Trastuzumab $\cdot$ Celecoxib

\section{Introduction}

Preoperative systemic therapy is now an established part of the management of large, potentially operable, and locally advanced breast cancers as it could achieve down-staging of the primary tumor, thereby allowing breast-conserving surgery [1-4]. Neoadjuvant therapy has been shown to be equivalent to adjuvant therapy in terms of survival and relapse-free survival [5]. The achievement of pathological complete response (pCR) including nodal involvement could be a surrogate marker to predict long-term outcome and is currently the main endpoint reported by neoadjuvant chemotherapy protocols [6-9]. Clinical trials in this setting therefore require fewer patients and can be completed more rapidly. However, not all patients achieving pCR will be cured and other surrogate markers must therefore be identified $[10,11]$.

Cyclooxygenase-2 (COX2), which mediates the production of prostaglandins and thromboxanes from 
arachidonic acid, is induced in inflammation and in cancer development and progression [12-15]. COX-2 is frequently over-expressed in breast cancer, and associated with unfavorable outcomes. Over-expression of COX2 in breast cancer cell lines increases cell migration and invasion [16]. Celecoxib is a COX-2 inhibitor with anti-angiogenic and pro-apoptotic activity. In breast cancer cells celecoxib analogs were shown to be potent inhibitors of phosphoAkt-signaling pathways and to induce apoptosis [17]. In animal models, treatment with selective COX-2 inhibitors reduced the formation, growth, microvasculature, and metastases of tumors [13].

Trastuzumab, a recombinant humanized monoclonal antibody targeting the HER 2 receptor, is clinically active in HER2 metastatic breast cancer when used alone or in combination with chemotherapy [18]. Large trials have established a survival benefit for trastuzumab in the adjuvant setting [19, 20]. A limited number of phase II trials have evaluated trastuzumab in combination with various chemotherapeutic agents in the neoadjuvant setting [2, 2124]. In these studies, the pCR rates obtained ranged from 12 to $47 \%$ [23]. Three randomized clinical trials have studied the combination of trastuzumab with a sequential regimen of anthracyclines-based chemotherapy then paclitaxel or docetaxel. In the M.D. Anderson group trial, the pCR rate was $25 \%$ in the chemotherapy-only arm versus $67 \%$ in the trastuzumab arm $[25,26]$. In the NOAH trial reported by Gianni et al. [27], the pCR rates were, respectively, $23 \%$ versus $43 \%(P=0.002)$ without or with trastuzumab. In the GeparQuattro, including 453 HER2 positive patients, pCR rates were, respectively, 20 and $41.3 \%$ without or with trastuzumab [28].

The aim of the present randomized phase II study was to assess anti-tumor activity of sequential epirubicin/cyclophosphamide followed by docetaxel with the randomized addition of celecoxib in HER2 negative tumor patients or trastuzumab in HER2 positive tumor patients in terms of pathological complete response.

\section{Patients and methods}

Patients and chemotherapy regimen

The randomized phase II Remagus 02 trial included patients from four different institutions. Eligibility criteria for the study were female patients over the age of 18 and under the age of 65 with histologically proven non-metastatic invasive breast carcinoma (Stage II and III), not amenable to breast-conserving surgery (diameter $>3 \mathrm{~cm}$, central) or with risk factors making neoadjuvant chemotherapy the preferred treatment (i.e., N2-N3, rapid growth rate). Inflammatory breast cancers were allowed.
Availability of frozen tumor tissue for molecular studies was mandatory. Eligible patients had no history of previous malignancy other than treated in situ carcinoma of the cervix or non-melanoma skin cancer, no bilateral breast cancer, and no distant metastasis. The routine diagnostic work-up included bilateral mammography and ultrasound, breast MRI, tumor biopsy with frozen sample, chest X-rays, abdominal ultrasound, bone scan, blood sampling, and clinical examination. Patients were eligible is Left Ventricular Ejection Fraction (LVEF) assessed by MUGA scan or ultrasound was $>50 \%$. HER2 status was considered positive if the immunohistochemistry result was $3+$ according to current ASCO criteria. In doubtful cases $(2+)$, a FISH analysis was performed. HER2 status was centrally reviewed for all patients and HER2 positivity confirmed by FISH in all cases. The cut-off used to define hormone receptor positivity was $10 \%$ of stained cells.

All patients were planned to receive epirubicin $\left(75 \mathrm{mg} / \mathrm{m}^{2}\right)$-cyclophosphamide $\quad\left(750 \mathrm{mg} / \mathrm{m}^{2}\right)$ intravenously every 3 weeks for four cycles followed by docetaxel $\left(100 \mathrm{mg} / \mathrm{m}^{2}\right)$ every 3 weeks for four cycles with or without trastuzumab $(8 \mathrm{mg} / \mathrm{kg}$ at first infusion then $6 \mathrm{mg} / \mathrm{kg}$ ) every 3 weeks, according to randomization, for HER2positive tumor patients and with or without celecoxib $400 \mathrm{mg}$ BID orally for HER2-negative tumor patients. Surgery (lumpectomy or modified radical mastectomy associated to axillary clearance) was performed 21-45 days after cycle 8, according to initial and postchemotherapy assessment (MRI evaluation was not mandatory). Conservative surgery was acceptable in the absence of multifocality provided clear margins were obtained. Surgery was followed by local and regional radiotherapy when indicated (in all cases of breast conserving surgery and/or in case of nodal involvement). The administration of adjuvant trastuzumab for a total of 18 three-weekly infusions was mandatory for all HER2positive cancer patients, to be started after surgery for those randomized to control. Indeed, all patients but eight received it. All patients with hormone receptor-positive tumors received adjuvant tamoxifen or aromatase inhibitors according to their menopausal status and the current guidelines. Adjuvant chemotherapy according to centers preferences in patients with residual axillary nodal involvement $(\mathrm{pN}+)$ could be delivered based on 5-fluorouracile and vinorelbine combination, concomitantly or not with radiotherapy (four cycles).

Clinical evaluation of tumor response was performed before each subsequent cycle, while mammogram, ultrasound and eventually MRI were repeated before cycle 5 and immediately before surgery.

Pathologic tumor response (primary tumor and axillary nodal status) was evaluated according to Chevallier criteria; a pCR was defined by Chevallier grade 1 or 2 criteria 
[29]: no residual invasive carcinoma in the breast and axillary nodes. All pathological responses were reviewed by the panel of pathologists blinded to the center and the treatment arm.

\section{Safety evaluations}

Safety evaluation procedures included clinical evaluations and blood tests initially and before each subsequent chemotherapy cycle. Patients with HER2-positive tumors had LVEF evaluation through the same procedure before initiation of treatment, before cycles 4 and 6 , plus before and after cycle 8 in the group receiving trastuzumab and subsequently every 3 months during adjuvant trastuzumab.

\section{Statistical methods}

The main criterion was pathologic tumor response according to Chevallier grade 1 or 2 [29]. A two-stage modified Fleming approach was proposed for each treatment groups, allowing stopping the study only in case of insufficient antitumor efficacy. In both strata, randomization was stratified on treating center.

For each group in Stratum A (HER2 negative), the percentage defined in null hypothesis was $15 \%$ and the expected percentage was $25 \%$ (a level of pathologic tumor response inferior or equal to $15 \%$ was considered as unacceptable leading to its discontinuation, whereas a level significantly above $15 \%$ as acceptable); inclusion of 110 patients by arm was needed to access the acceptable rate of $25 \%$ with a power of $90 \%$ and with $\alpha$ equal to $9 \%$. Concerning the decisions rules, if $22 \mathrm{pCR}$ or more were observed, evidence was provided that the strategy has to be continued. For each group in Stratum B (HER2 positive), the percentage defined in null hypothesis was $15 \%$ and the expected percentage was $30 \%$ (a level of pathologic tumor response inferior or equal to $15 \%$ was considered as unacceptable, whereas a level significantly above $15 \%$ as acceptable); inclusion of 60 patients by arm was needed to access the acceptable rate of $30 \%$ with a power of $90 \%$ and with $\alpha$ equal to $7 \%$. Concerning the decisions rules, if 14 pCR or more were observed, evidence was provided that the strategy has to be continued.

An intermediate analysis was to be conducted when half of the planned patients had been assessed in the groups in order to stop study arm(s) in case of insufficient efficacy. The study was not stopped at this stage (results not showed) and was conducted up to the end.

Differences between categorical variables were analyzed by $\chi^{2}$ tests or Fisher's exact test. No comparisons tests were made between the groups within each stratum: this study was a stratified randomized phase II conducted to evaluate the primary efficacy of each therapeutic strategy and not to compare the groups between them because of a lack of power in such a case.

Secondary end-points were clinical responses at cycles 4 and 8 , tolerance, disease-free survival, biomarkers studies, and analysis of markers predictive for pathological complete response in each group. Translational studies will be reported elsewhere. Survival data are not yet available. We therefore report here mature data on the main end-point (pathological complete response) together with data on tolerance and prediction of response in both strata.

Analyses were performed using R software 2.5.0 version.

\section{Results}

From May 2004 to October 2007, 341 patients were randomized in this trial. One patient was excluded for a major violation of the protocol and 340 were analyzed in intent to treat (Fig. 1, flow chart). Patients' characteristics are shown in Table 1. Within each stratum, groups were overall well balanced. Half of patients had T2 while half had T3-T4 tumors. It is important to highlight that tumors were large with $14 \%$ of T4 including T4d. None of patients with HER2 positive tumor had grade 1 carcinoma but $59 \%$ had expression of hormonal receptors.

Compliance to treatment was good: only four patients stopped for toxicity (1.2\%), 10 for tumor progression (3\%), and $10(3 \%)$ for various reasons (patient's decision, protocol violation, etc.). Altogether 212/220 patients in Stratum A were operated (104/108 in group A1, 108/112 in group A2), 214 had axillary sampling (106/112 in group A2); 119/120 patients in Stratum B were operated and all had axillary clearance. Therefore, 329 patients were evaluable for pathological response. For both strata (Table 2), the first step analysis at 110 and 60 patients in total indicated that the second step was to be conducted; the second step analysis after the recruitment of twofold the number of patients was performed until 340 eligible patients had been analyzed. In the HER2 negative group complete pathological rates were $11 \%$ without celecoxib versus $13 \%$ with celecoxib. According to sequential analysis and the decisions rules, at the second stage, as the number of pCR was below 21 , the null hypothesis of a pCR rate with celecoxib $\leq 15 \%$ could not be rejected. There was no apparent increase in response rate with the addition of celecoxib to sequential neoadjuvant chemotherapy.

For the group of patients with HER2 positive tumor, at the second step, the number of pCR was superior to 14 , the hypothesis of an increased efficacy of the combined arm trastuzumab + chemotherapy with pCR rate of $26 \%$ (95\% confidence interval 16-37\%) was confirmed providing evidence that this was a strategy to be continued. pCR rate was 19\% (95\% confidence interval 9-29\%) in 
Fig. 1 Flow chart of the REMAGUS 2 trial

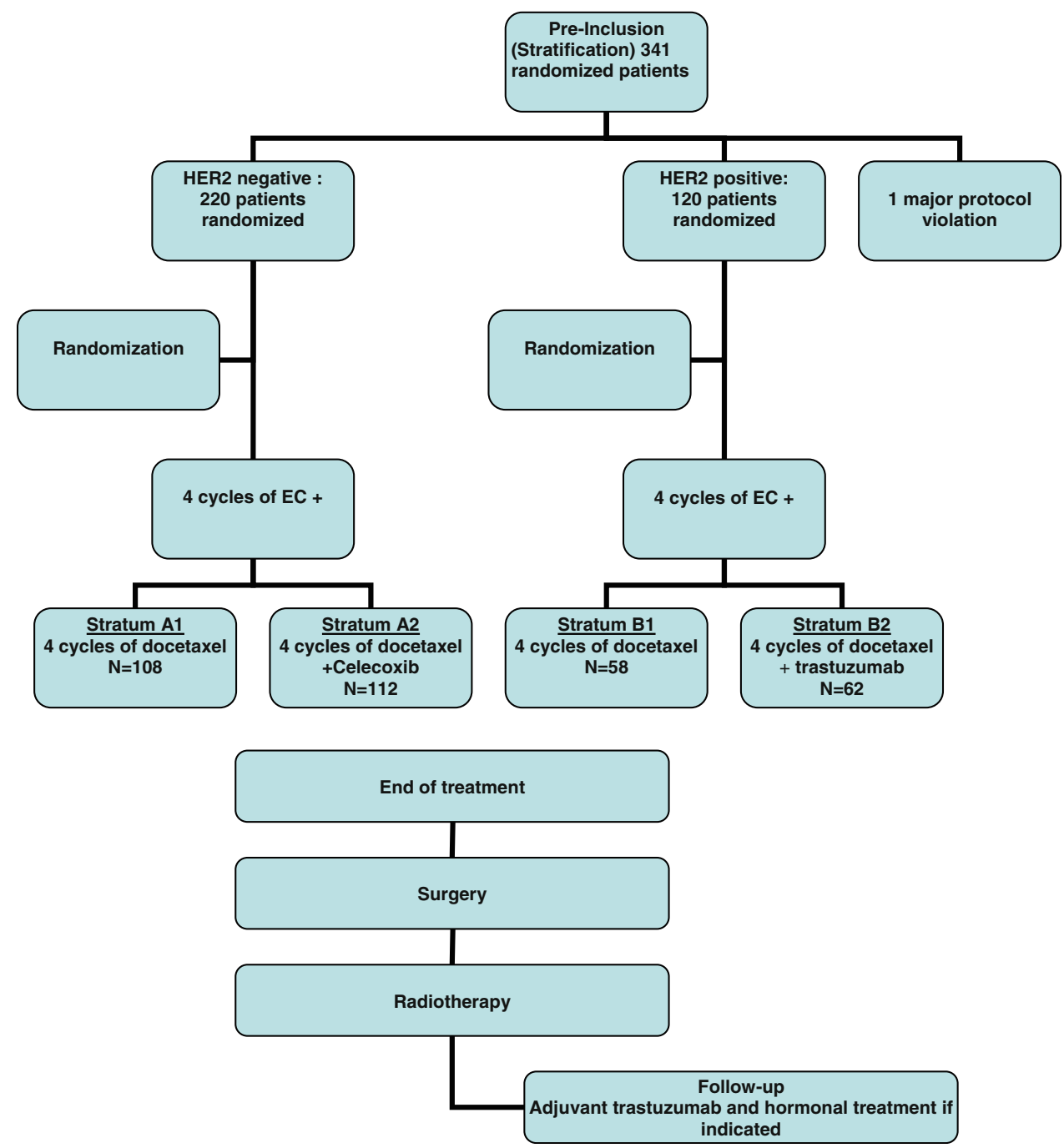

the chemotherapy alone arm. Grade 1 response (residual in situ carcinoma of the breast) rate was $7 \%(4 / 58)$ in the trastuzumab arm and $19 \%(12 / 62)$ in the arm without trastuzumab.

There were 78 triple negative breast cancers (23\%) in this study (Table 3). This subgroup of patients experienced the highest pCR rate, $29.5 \%$ (95\% confidence interval $19.7-40.9 \%$ ) compared to $11.4 \%$ in all the other subgroups or to $2 \%$ in the HER2 negative, hormonal receptors positive subgroup.

Clinical complete response rates between the four arms were: $26.9,23.2$, and $22.4 \%$, respectively, in the arms without trastuzumab and $33.9 \%$ in the arm with trastuzumab and clinical response rates (more than $50 \%$ tumor size reduction) were $77.8,72.3,86.2$, and $77.4 \%$, respectively. In this population with large tumor, not eligible for primary breast conservative surgery $50 \%$ (170/340) of the patients had lumpectomy with axillary dissection after neoadjuvant chemotherapy avoiding mastectomy. There was no suggestion of difference according to HER2 status and or therapeutic arm (Table 1).

There was no treatment-related death and no Sudden Unexpected Serious Adverse Event. Use of celecoxib in randomization in Stratum 1 (HER2 negative tumor patients) for a new patient was suspended by AFFSAPS (National French Health authorities) from December 2004 to September 2005 as part of the European assessment of cardiac side effects of coxib, and was thereafter authorized with revision of the informed consent form. Tolerance according to treatment arm is shown in Table 4.

Five (4.6\%) HER2 negative tumor patients without celecoxib had five episodes of skin rash compared to seven receiving celecoxib who had nine episodes of skin rash.

There was no obvious difference for other toxicities as shown in Table 2. Reduction of LEVF between 10 and $20 \%$ but with an absolute value $>50 \%$ was observed in $30(16.3 \%)$ of the evaluated patients. One patient had a reduction of LVEF below $50 \%(45 \%)$ in the arm receiving trastuzumab (B2). 
Table 1 Patients characteristics

\begin{tabular}{|c|c|c|c|c|c|c|c|}
\hline & \multirow[t]{2}{*}{$N(\%)$} & \multicolumn{3}{|l|}{ HER $2-N=220$} & \multicolumn{3}{|l|}{$\mathrm{HER} 2+N=120$} \\
\hline & & $\mathrm{Cx}-$ group $(108)$ & $\mathrm{Cx}+$ group (112) & Total & Trastu - group (58) & Trastu+ group (62) & Total \\
\hline Age & Median (SD) & $47(9.1)$ & $47(9.3)$ & 47 & $46.5(8.8)$ & $47(9.3)$ & 47 \\
\hline \multirow[t]{3}{*}{ Tumor size } & $\mathrm{T} 2$ & $55(51 \%)$ & $65(58 \%)$ & $120(55 \%)$ & $27(47 \%)$ & $32(52 \%)$ & $59(49 \%)$ \\
\hline & $\mathrm{T} 3$ & $33(31 \%)$ & $37(33 \%)$ & $70(32 \%)$ & $22(38 \%)$ & $21(34 \%)$ & $43(36 \%)$ \\
\hline & $\mathrm{T} 4$ & $20(18 \%)$ & $10(9 \%)$ & $30(13 \%)$ & $9(15.5 \%)$ & $9(14.5 \%)$ & $18(15 \%)$ \\
\hline \multirow[t]{4}{*}{ Clinical nodal status } & No & $42(39 \%)$ & $45(40 \%)$ & $87(40 \%)$ & $18(31 \%)$ & $25(40 \%)$ & $43(36 \%)$ \\
\hline & N1 & $58(54 \%)$ & $55(49 \%)$ & $113(51 \%)$ & $36(62 \%)$ & $34(55 \%)$ & $70(58 \%)$ \\
\hline & N2-N3 & $6(5 \%)$ & $12(11 \%)$ & $18(8 \%)$ & $3(5 \%)$ & $3(5 \%)$ & $6(5 \%)$ \\
\hline & NA & $2(2 \%)$ & $0(0 \%)$ & $2(1 \%)$ & $1(2 \%)$ & $0(0 \%)$ & $1(1 \%)$ \\
\hline \multirow[t]{4}{*}{ Tumor grade } & Grade 1 & $13(12 \%)$ & $7(6 \%)$ & $20(9 \%)$ & $0(0 \%)$ & $0(0 \%)$ & $0(0 \%)$ \\
\hline & Grade 2 & $41(38 \%)$ & $56(50 \%)$ & $97(44 \%)$ & $22(38 \%)$ & $25(40 \%)$ & $47(39 \%)$ \\
\hline & Grade 3 & $49(45 \%)$ & $47(42 \%)$ & $96(44 \%)$ & $32(55 \%)$ & $35(56 \%)$ & $67(56 \%)$ \\
\hline & Grade NA & $5(5 \%)$ & $2(2 \%)$ & $7(3 \%)$ & $4(7 \%)$ & $2(3 \%)$ & $6(5 \%)$ \\
\hline \multirow[t]{4}{*}{ Hormonal status } & $\mathrm{ER}+\mathrm{ve}$ & $73(68 \%)$ & $67(60 \%)$ & $140(64 \%)$ & $35(60 \%)$ & $32(52 \%)$ & $67(56 \%)$ \\
\hline & $\mathrm{PR}+\mathrm{ve}$ & $52(48 \%)$ & $46(41 \%)$ & $98(45 \%)$ & $21(36 \%)$ & $20(32 \%)$ & $41(34 \%)$ \\
\hline & NA & $1(0.9 \%)$ & $2(2 \%)$ & $3(1 \%)$ & $0(0 \%)$ & $1(2 \%)$ & $1(1 \%)$ \\
\hline & ER and PR- & $34(32 \%)$ & $44(39 \%)$ & $78(35 \%)$ & $21(36 \%)$ & $28(45 \%)$ & $49(41 \%)$ \\
\hline \multirow[t]{3}{*}{ Surgery } & Lumpectomy & $58(54 \%)$ & $56(50 \%)$ & $114(52 \%)$ & $27(47 \%)$ & $29(47 \%)$ & $56(47 \%)$ \\
\hline & Mastectomy & $46(43 \%)$ & $52(46 \%)$ & $98(45 \%)$ & $30(53 \%)$ & $33(53 \%)$ & $63(52 \%)$ \\
\hline & No surgery & $4(4 \%)$ & $4(4 \%)$ & $8(4 \%)$ & $1(2 \%)$ & $0(0 \%)$ & $1(1 \%)$ \\
\hline \multirow[t]{3}{*}{ Radiotherapy } & Yes & $101(99 \%)$ & $100(95 \%)$ & $201(97 \%)$ & $51(94 \%)$ & $57(92 \%)$ & $108(93 \%)$ \\
\hline & No & $1(1 \%)$ & $5(5 \%)$ & $6(3 \%)$ & $3(6 \%)$ & $5(8 \%)$ & $8(7 \%)$ \\
\hline & Missing data & 6 & 7 & 13 & 4 & 0 & 4 \\
\hline \multirow[t]{3}{*}{ Hormonotherapy } & Yes & $73(72 \%)$ & $66(62 \%)$ & $139(67 \%)$ & $28(52 \%)$ & $29(47.5 \%)$ & $57(49.5 \%)$ \\
\hline & No & $28(28 \%)$ & $40(38 \%)$ & $68(33 \%)$ & $26(48 \%)$ & $32(52.5 \%)$ & $58(50.5 \%)$ \\
\hline & Missing data & 7 & 6 & 13 & 4 & 1 & 5 \\
\hline \multirow[t]{3}{*}{ Systemic treatment ${ }^{\mathrm{a}}$} & Yes & $31(30 \%)$ & $30(28 \%)$ & $61(29 \%)$ & $48(89 \%)$ & $59(95 \%)$ & $107(92 \%)$ \\
\hline & No & $71(70 \%)$ & $76(72 \%)$ & $147(71 \%)$ & $6(11 \%)$ & $3(5 \%)$ & $9(8 \%)$ \\
\hline & Missing data & 6 & 6 & 12 & 4 & 0 & 4 \\
\hline
\end{tabular}

${ }^{a}$ Adjuvant chemotherapy and/or trastuzumab in HER2+ patients)

Table 2 Pathological response according to Chevallier criteria

\begin{tabular}{|c|c|c|c|c|c|}
\hline \multirow[t]{2}{*}{ Chevallier classification } & \multirow[t]{2}{*}{$N(\%)$} & \multicolumn{2}{|c|}{$\mathrm{HER} 2-N=220$} & \multicolumn{2}{|c|}{$\mathrm{HER} 2+N=120$} \\
\hline & & $\begin{array}{l}\mathrm{Cx}-\text { group } \\
N=108\end{array}$ & $\begin{array}{l}\mathrm{Cx}+\text { group } \\
N=112\end{array}$ & $\begin{array}{l}\text { Trastu- group } \\
N=58\end{array}$ & $\begin{array}{l}\text { Trastu+ group } \\
N=62\end{array}$ \\
\hline No residual disease and $\mathrm{pNO}$ & Grade 1 & $8(7 \%)$ & $11(10 \%)$ & $4(7 \%)$ & $12(19 \%)$ \\
\hline Breast CIS and pNO & Grade 2 & $4(4 \%)$ & $3(3 \%)$ & $7(12 \%)$ & $4(6.5 \%)$ \\
\hline Residual invasive carcinoma with treatment-induced changes & Grade 3 & $47(43.5 \%)$ & $51(45.5 \%)$ & $32(55 \%)$ & $31(50 \%)$ \\
\hline Minimally modified residual invasive carcinoma and/or $\mathrm{pN}+$ & Grade 4 & $49(45 \%)$ & $47(42 \%)$ & $15(26 \%)$ & $15(24 \%)$ \\
\hline Complete response & pCR (grade $1+2$ ) & $12(11 \%)$ & $14(13 \%)$ & $11(19 \%)$ & $16(25.5 \%)$ \\
\hline
\end{tabular}

\section{Discussion}

With pathological complete response being the primary endpoint, the addition of celecoxib to standard sequential epirubicin/cyclophosphamide-docetaxel in HER2 negative patients does not differ from the null hypothesis ( $\leq 15 \%$ pCR rate). Indeed the group of HER2 positive tumor patients with trastuzumab added to docetaxel with $26 \%$ (95\% confidence interval 16-37\%) pCR, was the only one for which the null hypothesis could be eliminated. The 
Table 3 Pathological response (Grade 1 and 2) according to hormonal receptor status and according to treatment arm in the HER2 positive tumor stratum

\begin{tabular}{llcl}
\hline & $\begin{array}{l}\text { ER+ and/or } \\
\text { PR+ }\end{array}$ & ER - and PR - Total \\
\hline HER2- & $3 / 142(2 \%)$ & $23 / 78(29.5 \%)$ & $24 / 220(10.9 \%)$ \\
HER2 + & & & \\
Trastuzumab- & $7 / 37(20.5 \%)$ & $4 / 21(19 \%)$ & $11 / 58(19 \%)$ \\
Trastuzumab+ & $7 / 34(20.5 \%)$ & $9 / 28(32 \%)$ & $16 / 62(26 \%)$ \\
Total & $14 / 71(19.7 \%)$ & $13 / 49(26.5 \%)$ & $27 / 120(22.5 \%)$ \\
\hline
\end{tabular}

pCR rate for the whole population is in the low range of reported values with similar sequential anthracyclines cyclophosphamide then taxanes chemotherapy regimen [30]. Among the possible explanations there is the fact that all cases were reviewed by the panel of pathologists with very strict criteria of $\mathrm{pCR}$ definition, using Chevallier classification including the nodal status. Also, the median tumor size was large and none of the patients was eligible for a breast conservative surgery before chemotherapy.

Chemotherapy with celecoxib was not able to demonstrate a promising $\mathrm{pCR}$ rate in our study. There are few results of anti-COX2 treatment in breast cancer. Further explorations with hormonal treatment have been reported without significant improvement in overall or progression free survival [31-33]. One phase II trial in 42 patients combined chemotherapy (capecitabine) and celecoxib in metastatic breast cancer patients showing an increased time to progression in case of COX2 over-expression [34]. Our study is the first randomized trial of combination of chemotherapy and COX2 inhibitor for localized breast cancer. However, the lower pCR rates in this study may underestimate the benefit of celecoxib. Tolerance was good with no cardiac event and a small trend for more frequent skin rashes. While this first analysis does not suggest increase pCR, however, longer follow-up will be necessary to ascertain reduction in the metastatic rate. As suggested by Lucci et al., COX2 produced in primary breast cancer cells may be vital to the initial development of bone marrow micrometastasis that may subsequently lead to osteolytic bone metastases in patients with breast cancer, and COX2 inhibitors may be useful in halting this process [16].

The pCR rate in patients increased to $26 \%$ (95\% confidence interval 16-37\%) in patients with HER2 positive tumor receiving chemotherapy and trastuzumab [23]. Higher response rates from 41 to $60 \%$ have been reported in the MD Anderson, NOAH and GeparQuattro trials [2628]. In these three studies, one should notice that trastuzumab was given upfront, for a longer period of time and was administered concurrently with an anthracyclinesbased chemotherapy regimen without so far overrated

Table 4 Treatment-related toxicity

\begin{tabular}{|c|c|c|c|c|c|c|c|c|}
\hline \multirow[t]{3}{*}{ Side effects } & \multicolumn{4}{|c|}{ Side effects $N(\%)$ during four cycles of EC } & \multicolumn{4}{|c|}{ Side effects $N(\%)$ during four cycles docetaxel } \\
\hline & \multicolumn{2}{|l|}{ HER2- } & \multicolumn{2}{|l|}{ HER2+ } & \multicolumn{2}{|l|}{ HER2- } & \multicolumn{2}{|l|}{ HER2 + } \\
\hline & $\begin{array}{l}\mathrm{Cx}-\text { group } \\
(N=108)\end{array}$ & $\begin{array}{l}\mathrm{Cx}+\text { group } \\
(N=112)\end{array}$ & $\begin{array}{l}\text { Trastu- group } \\
(N=58)\end{array}$ & $\begin{array}{l}\text { Trastu+ group } \\
(N=62)\end{array}$ & $\begin{array}{l}\mathrm{Cx}-\text { group } \\
(N=108)\end{array}$ & $\begin{array}{l}\mathrm{Cx}+\text { group } \\
(N=112)\end{array}$ & $\begin{array}{l}\text { Trastu- group } \\
(N=58)\end{array}$ & $\begin{array}{l}\text { Trastu+ group } \\
(N=62)\end{array}$ \\
\hline \multicolumn{9}{|l|}{ Skin and nails } \\
\hline Grade $1+2$ & $6(5.6 \%)$ & $5(4.50 \%)$ & $3(5.10 \%)$ & $3(4.8 \%)$ & $21(19.40 \%)$ & $32(28.6 \%)$ & $12(20.7 \%)$ & $13(21.0 \%)$ \\
\hline Grade 3 & $0(0 \%)$ & $0(0 \%)$ & $1(1.7 \%)$ & $0(0 \%)$ & $4(3.7 \%)$ & $3(2.7 \%)$ & $0(0 \%)$ & $2(3.2 \%)$ \\
\hline Grade 4 & $0(0 \%)$ & $1(0.9 \%)$ & $0(0 \%)$ & $0(0 \%)$ & $0(0 \%)$ & $0(0 \%)$ & $0(0 \%)$ & $2(3.2 \%)$ \\
\hline \multicolumn{9}{|l|}{ Neutropenia } \\
\hline Grade $1+2$ & $31(28.7 \%)$ & $30(26.7 \%)$ & $12(20.7 \%)$ & $22(35.5 \%)$ & $14(13.0 \%)$ & $7(6.3 \%)$ & $6(10.4 \%)$ & $5(8.0 \%)$ \\
\hline Grade 3 & $31(28.7 \%)$ & $36(32.1 \%)$ & $16(27.6 \%)$ & $16(25.8 \%)$ & $18(16.7 \%)$ & $18(16.1 \%)$ & $9(15.5 \%)$ & $9(14.5 \%)$ \\
\hline Grade 4 & $24(22.2 \%)$ & $28(25 \%)$ & $22(37.9 \%)$ & $16(25.8 \%)$ & $36(33.3 \%)$ & $44(39.3 \%)$ & $19(32.8 \%)$ & $28(45.2 \%)$ \\
\hline \multicolumn{9}{|c|}{ Febrile neutropenia } \\
\hline Grade 3 & $8(7.4 \%)$ & $8(7.1 \%)$ & $3(5.2 \%)$ & $5(8.1 \%)$ & $10(9.2 \%)$ & $12(10.7 \%)$ & $7(12.0 \%)$ & $11(17.7 \%)$ \\
\hline \multicolumn{9}{|l|}{ Fatigue } \\
\hline Grade $1+2$ & $73(67.3 \%)$ & $90(80.4 \%)$ & $42(72.5 \%)$ & $43(69.4 \%)$ & $72(66.7 \%)$ & $70(62.6 \%)$ & $35(60.4 \%)$ & $43(69.3 \%)$ \\
\hline Grade $3 / 4$ & $2(1.9 \%)$ & $0(0 \%)$ & $2(3.4 \%)$ & $0(0 \%)$ & $2(1.9 \%)$ & $2(1.8 \%)$ & $2(3.4 \%)$ & $0(0 \%)$ \\
\hline \multicolumn{9}{|l|}{ Mucositis } \\
\hline Grade $1+2$ & $31(28.7 \%)$ & $37(33.1 \%)$ & $17(29.3 \%)$ & $17(27.4 \%)$ & $41(22.2 \%)$ & $31(37.9 \%)$ & $31(39.6 \%)$ & $22(35.5 \%)$ \\
\hline Grade $3 / 4$ & $0(0 \%)$ & $1(0.9 \%)$ & $0(0 \%)$ & $0(0 \%)$ & $4(3.7 \%)$ & $0(0 \%)$ & $4(6.9 \%)$ & $2(3.2 \%)$ \\
\hline \multicolumn{9}{|l|}{ Diarrhea } \\
\hline Grade $1+2$ & $8(7.4 \%)$ & $13(11.6 \%)$ & $7(12.0 \%)$ & $6(9.7 \%)$ & $27(25.0 \%)$ & $28(25.0 \%)$ & $16(27.6 \%)$ & $12(19.3 \%)$ \\
\hline Grade $3 / 4$ & $0(0 \%)$ & $0(0 \%)$ & $0(0 \%)$ & $0(0 \%)$ & $0(0 \%)$ & $1(0.9 \%)$ & $0(0 \%)$ & $0(0 \%)$ \\
\hline
\end{tabular}


cardiac consequences. However, caution must be advised regarding the concomitant use of trastuzumab with anthracyclines [19]. In our study, one should pay attention to the absence of cardiac event. Our results with a low response rate despite trastuzumab addition substantiates a very early introduction of trastuzumab in the sequence of the neoadjuvant chemotherapy and of the possible higher efficacy of the combination with anthracyclines, targeting also topoisomerase II which can be more often amplified in HER2 over-expressing tumor .

Interestingly, grade 2 response (residual ductal carcinoma in situ DCIS only) was reduced in the trastuzumab receiving arm, $6.5 \%$ versus $12 \%$ without trastuzumab in the subgroup of HER2 positive tumor patient. This has to be put in perspective with the description of higher rate of HER2 over-expression in DCIS around $60 \%$ and the possible impact of trastuzumab on DCIS; clinical trials by the MD Anderson and the NSABP are ongoing in this setting [35].

Response rate according to hormonal status in HER2 positive tumor patients did not show important variations. We observed a trend for a higher response rate with the addition of trastuzumab predominantly in the estrogen receptor negative subgroup of patients. This is in contradiction with Peinteiger et al. [36] reporting a higher pCR rate in the HR+ subgroup with the addition of trastuzumab in neoadjuvant setting. In our study, patients with triple negative breast cancer had exquisite sensitivity to the chemotherapy regimen with a pCR rate of $30 \%$ compared to $2 \%$ in the RH + HER negative subgroup. Sensitivity of ER negative breast to neoadjuvant chemotherapy has been previously reported [30,37, 38]. Despite fewer available data with triple negative this phenotype appears to be a strong predictor of chemosensitivity $[39,40]$. The relation of the phenotype with gene expression profiling, P53 mutational status as suggested with a dose dense regimen has been reported [41].

Although pCR is an accepted endpoint in neoadjuvant studies, it does not always correlate to an overall survival or disease-free survival benefit, e.g., NSABP 27 showed no improvement in OS/DFS with taxanes despite a doubling in pCR [30]. Those patients who do not achieve pCR may still have a good outcome. However, a recent report of Southern Italy Cooperative Oncology Group (SICOG) randomized trial 9908 shows that a significant increase in pCR rate after neoadjuvant chemotherapy for locally advanced breast cancer can be translated into RFS and OS improvement after median follow-up of 74 months [42].

\section{Conclusions}

There is no evidence of an increase in pCR with the addition of anti-COX2 treatment to neoadjuvant chemotherapy in HER2 negative breast cancer. There is an increase in pCR with the addition of trastuzumab to neoadjuvant $\mathrm{CT}$ in HER2 positive tumor bearing patients but with a lower rate than reported in the literature when trastuzumab is used concomitantly with anthracyclines. This could suggest that the interest of an earlier introduction of trastuzumab with or without anthracyclines in the neoadjuvant chemotherapy sequence to obtain a higher response rate. Longer follow-up is mandatory to prove if the increased pCR rate translates in gain in survival. Results of the expression microarrays study on all initial frozen biopsies are awaited in order to predict more accurately response to treatment.

Acknowledgments The authors would like to thank Dr Olivier Tembo for study monitoring and Jocelyne Goubet for data management. This study was supported by a grant of the French Programme Hospitalier de Recherche Clinique ISRCTN10059974, PHRC: AOM 0211 and by unrestricted grants from Pfizer Inc. France, Roche Pharmaceutical, and Sanofi-Aventis.

\section{References}

1. Jones RL, Smith IE (2006) Neoadjuvant treatment for early-stage breast cancer: opportunities to assess tumour response. Lancet Oncol 7:869-874

2. Untch M, von Minckwitz G (2009) Recent advances in systemic therapy. Advances in neoadjuvant (primary) systemic therapy with cytotoxic agents. Breast Cancer Res 11:203

3. Kaufmann M, von Minckwitz G, Bear HD, Buzdar A, McGale P, Bonnefoi H, Colleoni M, Denkert C, Eiermann W, Jackesz R, Makris A, Miller W, Pierga JY, Semiglazov V, Schneeweiss A, Souchon R, Stearns V, Untch M, Loibl S (2007) Recommendations from an international expert panel on the use of neoadjuvant (primary) systemic treatment of operable breast cancer: new perspectives 2006. Ann Oncol 18:1927-1934

4. Gralow JR, Burstein HJ, Wood W, Hortobagyi GN, Gianni L, von Minckwitz G, Buzdar AU, Smith IE, Symmans WF, Singh B, Winer EP (2008) Preoperative therapy in invasive breast cancer: pathologic assessment and systemic therapy issues in operable disease. J Clin Oncol 26:814-819

5. Mauri D, Pavlidis N, Ioannidis JP (2005) Neoadjuvant versus adjuvant systemic treatment in breast cancer: a meta-analysis. J Natl Cancer Inst 97:188-194

6. Rastogi P, Anderson SJ, Bear HD, Geyer CE, Kahlenberg MS, Robidoux A, Margolese RG, Hoehn JL, Vogel VG, Dakhil SR, Tamkus D, King KM, Pajon ER, Wright MJ, Robert J, Paik S, Mamounas EP, Wolmark N (2008) Preoperative chemotherapy: updates of National Surgical Adjuvant Breast and Bowel Project Protocols B-18 and B-27. J Clin Oncol 26:778-785

7. Cleator SJ, Makris A, Ashley SE, Lal R, Powles TJ (2005) Good clinical response of breast cancers to neoadjuvant chemoendocrine therapy is associated with improved overall survival. Ann Oncol 16:267-272

8. Pierga JY, Mouret E, Dieras V, Laurence V, Beuzeboc P, Dorval T, Palangie T, Jouve M, Vincent-Salomon A, Scholl S, Extra JM, Asselain B, Pouillart P (2000) Prognostic value of persistent node involvement after neoadjuvant chemotherapy in patients with operable breast cancer. Br J Cancer 83:1480-1487

9. Symmans WF, Peintinger F, Hatzis C, Rajan R, Kuerer H, Valero V, Assad L, Poniecka A, Hennessy B, Green M, Buzdar AU, Singletary SE, Hortobagyi GN, Pusztai L (2007) Measurement of 
residual breast cancer burden to predict survival after neoadjuvant chemotherapy. J Clin Oncol 25:4414-4422

10. Guarneri V, Frassoldati A, Giovannelli S, Borghi F, Conte P (2007) Primary systemic therapy for operable breast cancer: a review of clinical trials and perspectives. Cancer Lett 248:175-185

11. Hennessy BT, Hortobagyi GN, Rouzier R, Kuerer H, Sneige N, Buzdar AU, Kau SW, Fornage B, Sahin A, Broglio K, Singletary SE, Valero V (2005) Outcome after pathologic complete eradication of cytologically proven breast cancer axillary node metastases following primary chemotherapy. J Clin Oncol 23:9304-9311

12. Wang D, Dubois RN (2004) Cyclooxygenase-2: a potential target in breast cancer. Semin Oncol 31:64-73

13. Wang D, DuBois RN (2004) Cyclooxygenase 2-derived prostaglandin E2 regulates the angiogenic switch. Proc Natl Acad Sci USA 101:415-416

14. Dang CT, Shapiro CL, Hudis CA (2002) Potential role of selective COX-2 inhibitors in cancer management. Oncology (Williston Park) 16:30-36

15. Xu XC (2002) COX-2 inhibitors in cancer treatment and prevention, a recent development. Anticancer Drugs 13:127-137

16. Lucci A, Krishnamurthy S, Singh B, Bedrosian I, Meric-Bernstam F, Reuben J, Broglio K, Mosalpuria K, Lodhi A, Vincent L, Cristofanilli M (2009) Cyclooxygenase-2 expression in primary breast cancers predicts dissemination of cancer cells to the bone marrow. Breast Cancer Res Treat 117:61-68

17. Kucab JE, Lee C, Chen CS, Zhu J, Gilks CB, Cheang M, Huntsman D, Yorida E, Emerman J, Pollak M, Dunn SE (2005) Celecoxib analogues disrupt Akt signaling, which is commonly activated in primary breast tumours. Breast Cancer Res 7:R796R807

18. Marty M, Cognetti F, Maraninchi D, Snyder R, Mauriac L, Tubiana-Hulin M, Chan S, Grimes D, Anton A, Lluch A, Kennedy J, O'Byrne K, Conte P, Green M, Ward C, Mayne K, Extra JM (2005) Randomized phase II trial of the efficacy and safety of trastuzumab combined with docetaxel in patients with human epidermal growth factor receptor 2-positive metastatic breast cancer administered as first-line treatment: the M77001 study group. J Clin Oncol 23:4265-4274

19. Mariani G, Fasolo A, De Benedictis E, Gianni L (2009) Trastuzumab as adjuvant systemic therapy for HER2-positive breast cancer. Nat Clin Pract Oncol 6:93-104

20. Madarnas Y, Trudeau M, Franek JA, McCready D, Pritchard KI, Messersmith H (2008) Adjuvant/neoadjuvant trastuzumab therapy in women with HER-2/neu-overexpressing breast cancer: a systematic review. Cancer Treat Rev 34:539-557

21. Burstein HJ, Harris LN, Gelman R, Lester SC, Nunes RA, Kaelin CM, Parker LM, Ellisen LW, Kuter I, Gadd MA, Christian RL, Kennedy PR, Borges VF, Bunnell CA, Younger J, Smith BL, Winer EP (2003) Preoperative therapy with trastuzumab and paclitaxel followed by sequential adjuvant doxorubicin/cyclophosphamide for HER2 overexpressing stage II or III breast cancer: a pilot study. J Clin Oncol 21:46-53

22. Limentani SA, Brufsky AM, Erban JK, Jahanzeb M, Lewis D (2007) Phase II study of neoadjuvant docetaxel, vinorelbine, and trastuzumab followed by surgery and adjuvant doxorubicin plus cyclophosphamide in women with human epidermal growth factor receptor 2-overexpressing locally advanced breast cancer. J Clin Oncol 25:1232-1238

23. Lazaridis G, Pentheroudakis G, Pavlidis N (2008) Integrating trastuzumab in the neoadjuvant treatment of primary breast cancer: accumulating evidence of efficacy, synergy and safety. Crit Rev Oncol Hematol 66:31-41

24. Coudert BP, Largillier R, Arnould L, Chollet P, Campone M, Coeffic D, Priou F, Gligorov J, Martin X, Trillet-Lenoir V, Weber B, Bleuse JP, Vasseur B, Serin D, Namer M (2007) Multicenter phase II trial of neoadjuvant therapy with trastuzumab, docetaxel, and carboplatin for human epidermal growth factor receptor-2overexpressing stage II or III breast cancer: results of the GETN(A)-1 trial. J Clin Oncol 25:2678-2684

25. Buzdar AU, Ibrahim NK, Francis D, Booser DJ, Thomas ES, Theriault RL, Pusztai L, Green MC, Arun BK, Giordano SH, Cristofanilli M, Frye DK, Smith TL, Hunt KK, Singletary SE, Sahin AA, Ewer MS, Buchholz TA, Berry D, Hortobagyi GN (2005) Significantly higher pathologic complete remission rate after neoadjuvant therapy with trastuzumab, paclitaxel, and epirubicin chemotherapy: results of a randomized trial in human epidermal growth factor receptor 2-positive operable breast cancer. J Clin Oncol 23:3676-3685

26. Buzdar AU, Valero V, Ibrahim NK, Francis D, Broglio KR, Theriault RL, Pusztai L, Green MC, Singletary SE, Hunt KK, Sahin AA, Esteva F, Symmans WF, Ewer MS, Buchholz TA, Hortobagyi GN (2007) Neoadjuvant therapy with paclitaxel followed by 5 -fluorouracil, epirubicin, and cyclophosphamide chemotherapy and concurrent trastuzumab in human epidermal growth factor receptor 2-positive operable breast cancer: an update of the initial randomized study population and data of additional patients treated with the same regimen. Clin Cancer Res 13:228-233

27. Gianni L, Eiermann W, Semiglazov V, Manikhas A, Lluch A, Tjulandin S, Zambetti M, Vazquez F, Byakhow M, Lichinitser M, Climent MA, Ciruelos E, Ojeda B, Mansutti M, Bozhok A, Baronio R, Feyereislova A, Barton C, Valagussa P, Baselga J (2010) Neoadjuvant chemotherapy with trastuzumab followed by adjuvant trastuzumab versus neoadjuvant chemotherapy alone, in patients with HER2-positive locally advanced breast cancer (the NOAH trial): a randomised controlled superiority trial with a parallel HER2-negative cohort. Lancet 375:377-384

28. Untch M, Rezai M, Loibl S, Fasching PA, Huober J, Tesch H, Bauerfeind I, Hilfrich J, Eidtmann H, Gerber B, Hanusch C, Kuhn T, du Bois A, Blohmer JU, Thomssen C, Dan Costa S, Jackisch C, Kaufmann M, Mehta K, von Minckwitz G (2010) Neoadjuvant treatment with trastuzumab in HER2-positive breast cancer: results from the GeparQuattro study. J Clin Oncol 28:2024-2031

29. Chevallier B, Roche H, Olivier JP, Chollet P, Hurteloup P (1993) Inflammatory breast cancer. Pilot study of intensive induction chemotherapy (FEC-HD) results in a high histologic response rate. Am J Clin Oncol 16:223-228

30. Bear HD, Anderson S, Smith RE, Geyer CE Jr, Mamounas EP, Fisher B, Brown AM, Robidoux A, Margolese R, Kahlenberg MS, Paik S, Soran A, Wickerham DL, Wolmark N (2006) Sequential preoperative or postoperative docetaxel added to preoperative doxorubicin plus cyclophosphamide for operable breast cancer: National Surgical Adjuvant Breast and Bowel Project Protocol B-27. J Clin Oncol 24:2019-2027

31. Falandry C, Debled M, Bachelot T, Delozier T, Cretin J, Romestaing P, Mille D, You B, Mauriac L, Pujade-Lauraine E, Freyer $G$ (2008) Celecoxib and exemestane versus placebo and exemestane in postmenopausal metastatic breast cancer patients: a double-blind phase III GINECO study. Breast Cancer Res Treat

32. Dirix LY, Ignacio J, Nag S, Bapsy P, Gomez H, Raghunadharao D, Paridaens R, Jones S, Falcon S, Carpentieri M, Abbattista A, Lobelle JP (2008) Treatment of advanced hormone-sensitive breast cancer in postmenopausal women with exemestane alone or in combination with celecoxib. J Clin Oncol 26:1253-1259

33. Falandry C, Canney PA, Freyer G, Dirix LY (2009) Role of combination therapy with aromatase and cyclooxygenase-2 inhibitors in patients with metastatic breast cancer. Ann Oncol 20:615-620

34. Fabi A, Metro G, Papaldo P, Mottolese M, Melucci E, Carlini P, Sperduti I, Russillo M, Gelibter A, Ferretti G, Tomao S, Milella 
M, Cognetti F (2008) Impact of celecoxib on capecitabine tolerability and activity in pretreated metastatic breast cancer: results of a phase II study with biomarker evaluation. Cancer Chemother Pharmacol 62:717-725

35. Boughey JC, Gonzalez RJ, Bonner E, Kuerer HM (2007) Current treatment and clinical trial developments for ductal carcinoma in situ of the breast. Oncologist 12:1276-1287

36. Peintinger F, Buzdar AU, Kuerer HM, Mejia JA, Hatzis C, Gonzalez-Angulo AM, Pusztai L, Esteva FJ, Dawood SS, Green MC, Hortobagyi GN, Symmans WF (2008) Hormone receptor status and pathologic response of HER2-positive breast cancer treated with neoadjuvant chemotherapy and trastuzumab. Ann Oncol 19:2020-2025

37. Colleoni M, Viale G, Zahrieh D, Pruneri G, Gentilini O, Veronesi P, Gelber RD, Curigliano G, Torrisi R, Luini A, Intra M, Galimberti V, Renne G, Nole F, Peruzzotti G, Goldhirsch A (2004) Chemotherapy is more effective in patients with breast cancer not expressing steroid hormone receptors: a study of preoperative treatment. Clin Cancer Res 10:6622-6628

38. Ring AE, Smith IE, Ashley S, Fulford LG, Lakhani SR (2005) Oestrogen receptor status, pathological complete response and prognosis in patients receiving neoadjuvant chemotherapy for early breast cancer. Br J Cancer 92:906-912
39. Liedtke C, Mazouni C, Hess KR, Andre F, Tordai A, Mejia JA, Symmans WF, Gonzalez-Angulo AM, Hennessy B, Green M, Cristofanilli M, Hortobagyi GN, Pusztai L (2008) Response to neoadjuvant therapy and long-term survival in patients with triple-negative breast cancer. J Clin Oncol 26:1275-1281

40. Rouzier R, Perou CM, Symmans WF, Ibrahim N, Cristofanilli M, Anderson K, Hess KR, Stec J, Ayers M, Wagner P, Morandi P, Fan C, Rabiul I, Ross JS, Hortobagyi GN, Pusztai L (2005) Breast cancer molecular subtypes respond differently to preoperative chemotherapy. Clin Cancer Res 11:5678-5685

41. Bertheau P, Turpin E, Rickman DS, Espie M, de Reynies A, Feugeas JP, Plassa LF, Soliman H, Varna M, de Roquancourt A, Lehmann-Che J, Beuzard Y, Marty M, Misset JL, Janin A, de The H (2007) Exquisite sensitivity of TP53 mutant and basal breast cancers to a dose-dense epirubicin-cyclophosphamide regimen. PLoS Med 4:e90

42. Frasci G, D'Aiuto G, Comella P, D'Aiuto M, Di Bonito M, Ruffolo P, Iodice G, Petrillo A, Lastoria S, Oliviero P, Capasso I, Montella M, Siani C, Santangelo M, Vizioli L, Comella G (2010) Preoperative weekly cisplatin, epirubicin, and paclitaxel (PET) improves prognosis in locally advanced breast cancer patients: an update of the Southern Italy Cooperative Oncology Group (SICOG) randomised trial 9908. Ann Oncol 21:707-716 